\title{
A Telencephalic Nucleus Essential for Song Learning Contains Neurons with Physiological Characteristics of Both Striatum and Globus Pallidus
}

\author{
Michael A. Farries ${ }^{1}$ and David J. Perkel ${ }^{2}$ \\ ${ }^{1}$ Department of Neuroscience, University of Pennsylvania, Philadelphia, Pennsylvania 19104, and ${ }^{2}$ Departments of \\ Zoology and Otolaryngology, University of Washington Medical Center, Seattle, Washington 98195-6115
}

The song system of oscine birds has frequently been presented as a model system for motor learning in vertebrates. This practice has been bolstered by the growing recognition that one part of the song system that is essential for song learning, area $X$, is a component of the avian striatum. The mammalian striatum, the input structure of the basal ganglia, has been implicated in a number of motor-related functions, including motor learning, suggesting that song learning in birds and motor learning in mammals may use similar physiological mechanisms. We studied the intrinsic physiological properties of area $X$ neurons in brain slices to see how closely they match properties identified in mammalian striatal neurons and to collect data that are necessary to understand how area $\mathrm{X}$ pro- cesses information. We found that area $X$ contains all four physiological cell types present in the mammalian striatum and that each is very similar to its mammalian counterpart. We also found a fifth cell type in area $X$ that has not been reported in mammalian striatum; instead, this cell type resembles neurons that have been recorded in the mammalian globus pallidus. This pallidum-like cell type morphologically resembles the projection neurons of area $X$. We suggest that area $X$ contains a pathway equivalent to the "direct" striatopallidothalamic pathway through the mammalian basal ganglia, with the striatal and pallidal components intermingled in one nucleus.

Key words: songbird; striatum; basal ganglia; motor learning; area $X$; song learning
Birdsong has emerged as one of the leading models for studying motor learning in vertebrates, combining an easily quantified, naturally learned behavior with a circumscribed neural substrate. That neural substrate consists of a motor pathway that is required for singing (Nottebohm et al., 1976) and an anterior forebrain pathway (AFP) that is not required for singing per se, but is required for song learning (Fig. 1) (Bottjer et al., 1984; Sohrabji et al., 1990; Scharff and Nottebohm, 1991). The AFP appears to process song-related auditory feedback (Doupe and Konishi, 1991; Doupe, 1997) and is hypothesized to calculate some sort of error signal that guides the motor pathway to produce the target song (Brainard and Doupe, 2001). Our goal is to understand the physiological mechanisms by which this signal is generated and transmitted, focusing on the first nucleus of the AFP, area X.

Area $\mathrm{X}$ is a component of the avian basal ganglia, lying in a region identified previously as a homolog of the striatum (for review, see Medina and Reiner, 1995), the input structure of the basal ganglia. Like the mammalian striatum, area $\mathrm{X}$ has GABAergic projection neurons (Luo and Perkel, 1999b) and putative interneuron populations containing choline acetyltrans-

\footnotetext{
Received Oct. 2, 2001; revised Jan. 23, 2002; accepted Jan. 25, 2002.

This work was supported by a National Science Foundation Graduate Research Fellowship to M.A.F., a predoctoral National Research Service Award awarded by the National Institute of Mental Health to M.A.F., National Institutes of Health (NIH) Grant RO1 MH56646 to D.J.P., National Science Foundation Grant IBN 0196104 to D.J.P., and NIH/National Institute on Deafness and Other Communication Disorders Core Grant DC04661. We thank Dr. G. Ball for generously providing the starlings used in this study. We also thank Dr. M. Solis for helpful comments on early drafts of this paper.

Correspondence should be addressed to Dr. David J. Perkel, Departments of Zoology and Otolaryngology, University of Washington Medical Center, Box 356515, 1959 Northeast Pacific Street, Seattle, WA 98195-6115. E-mail: perkel@u.washington.edu.

Copyright (C) 2002 Society for Neuroscience $0270-6474 / 02 / 223776-12 \$ 15.00 / 0$
}

ferase (ChAT) (Zuschratter and Scheich, 1990), nitric oxide synthase (Wallhäusser-Franke et al., 1995), and parvalbumin (Meade et al., 1998). Given these histochemical similarities, area X neurons could also share some of characteristic physiological properties of the mammalian striatum. Knowing the intrinsic physiological properties of area $\mathrm{X}$ neurons is essential for understanding how it processes and transmits information, and if they prove to be similar to mammalian striatal neurons, it would suggest that the two structures use comparable mechanisms to carry out their respective functions. Moreover, one function ascribed to the mammalian striatum is a role in motor learning (Graybiel et al., 1994; Doya, 2000), so concordant physiological properties in area $\mathrm{X}$ and the mammalian striatum offer the possibility that research in the song system will be directly applicable to mammals.

Some problems with this conjecture are apparent at the outset, however. Area X projects directly to the thalamus (Okuhata and Saito, 1987; Bottjer et al., 1989), whereas the mammalian striatum communicates with the thalamus via the globus pallidus (Parent and Hazrati, 1995). The lack of an intervening pallidal structure between area $\mathrm{X}$ and the thalamus also highlights an apparent inconsistency in how auditory information is transmitted through area X. Excitatory auditory responses to the bird's own song have been recorded both upstream (McCasland and Konishi, 1981; Margoliash, 1983) and downstream (Doupe and Konishi, 1991) of area $\mathrm{X}$, yet one might naively expect area $\mathrm{X}$ to convert an excitatory response into an inhibitory one via its GABAergic projection neurons. This sign reversal would be counteracted by a second GABAergic relay through a pallidal structure, if it existed. To address questions concerning the organization of area $\mathrm{X}$ and its relationship to the mammalian basal ganglia, and to gain essential information on the intrinsic physiological properties of 


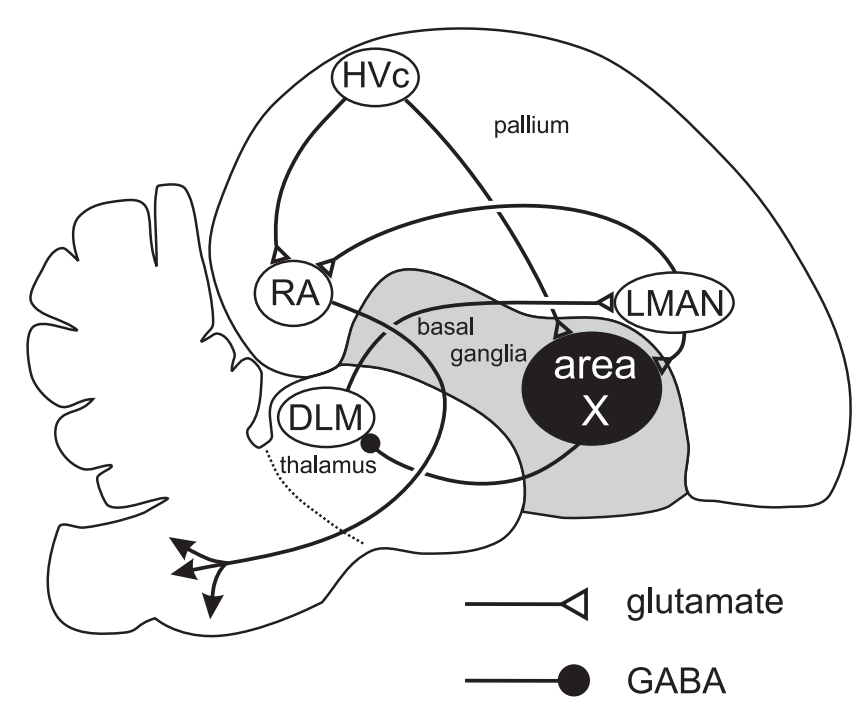

Figure 1. Diagram of the oscine song system in a schematic parasagittal section of the avian brain. The motor pathway begins with HVc (used as a proper name, not an abbreviation; Fortune and Margoliash, 1995), which projects to the nucleus robustus of the archistriatum (RA) (Nottebohm et al., 1976). RA projects to several brainstem nuclei concerned with respiration and vocalization (Nottebohm et al., 1976; Wild, 1993) that are not shown explicitly in this figure. HVc also projects to the AFP, beginning with area X (Nottebohm et al., 1976). Area X projects to the medial portion of the dorsolateral anterior thalamic nucleus $(D L M)$ (Okuhata and Saito, 1987; Bottjer et al., 1989), DLM projects to lateral magnocellular nucleus of the anterior neostriatum $(L M A N)$ (Bottjer et al., 1989), and LMAN completes the circuit by projecting to RA (Nottebohm et al., 1982) and to area X (Nixdorf-Bergweiler et al., 1995; Vates and Nottebohm, 1995). Most of the forebrain song system nuclei are in the pallium (HVc, RA, and LMAN) or thalamus (DLM) and have glutamatergic projection neurons. Area X, however, is a component of the avian basal ganglia (shown in gray) and has GABAergic projection neurons.

its neurons, we made whole-cell current-clamp recordings from area $\mathrm{X}$ in several songbird species.

Parts of this paper have been published previously in abstract form (Farries and Perkel, 1998).

\section{MATERIALS AND METHODS}

Preparation of brain slices. The bird species used in this study were purchased from a local supplier (zebra finches, Bengalese finches, and canaries), raised in our own breeding colony (juvenile zebra finches), collected in the wild and hand-reared (one white-crowned sparrow), or generously provided by Dr. G. Ball (Johns Hopkins University, Baltimore, MD) (starlings). Adult zebra finches (Taeniopygia guttata) were housed three to five per cage, whereas juvenile zebra finches raised in our colony were kept in cages containing only their parents and siblings. Other avian species were housed individually until they were used. Birds were kept on a 13/11 hr light/dark cycle, except for starlings, which were kept on an 11/13 hr cycle. Slices were prepared as described by Stark and Perkel (1999). The procedures were approved by the Institutional Animal Care and Use Committees at the University of Pennsylvania and the University of Washington. Briefly, birds were anesthetized with isoflurane or halothane and killed by decapitation. The brain was quickly removed and immersed in ice-cold artificial CSF (ACSF) containing (in $\mathrm{mM}$ ): $119 \mathrm{NaCl}, 2.5 \mathrm{KCl}, 1.3 \mathrm{MgSO}_{4}, 2.5 \mathrm{CaCl}_{2}, 1 \mathrm{NaH}_{2} \mathrm{PO}_{4}, 26.2$ $\mathrm{NaHCO}_{3}$, and 11 D-glucose. Parasagittal or coronal brain slices, 300-400 $\mu \mathrm{m}$ thick, were cut using a vibrating microtome and collected in ACSF (usually heated to $30^{\circ} \mathrm{C}$, sometimes at room temperature). On occasion, a modified ACSF was used during slicing (but not during slice storage or recording) containing $10 \mathrm{~mm} \mathrm{HEPES}$ and only $16.2 \mathrm{~mm} \mathrm{NaHCO}_{3}$, but which was otherwise identical to ACSF described above. All solutions were bubbled with a mixture of $95 \% \mathrm{O}_{2}$ and $5 \% \mathrm{CO}_{2}$.

Electrophysiological recording. Slices were placed in a recording chamber and superfused with ACSF at $24-27^{\circ} \mathrm{C}$. We recorded using the "blind" (Blanton et al., 1989) or visualized (Edwards et al., 1989) whole- cell techniques. Recording pipettes had a resistance of 4-9 M $\Omega$ and were filled with a solution containing (in mM): $120 \mathrm{~K}$ gluconate or K methylsulfate, 10 HEPES, 2 EGTA, $8 \mathrm{NaCl}, 2 \mathrm{MgATP}$, and $0.3 \mathrm{MgGTP}$. The osmolarity and $\mathrm{pH}$ of this solution were adjusted to $275-285 \mathrm{mOsm}$ and 7.2-7.4, respectively. We did not observe any differences in recordings made with $\mathrm{K}$ gluconate versus those made with $\mathrm{K}$ methylsulfate. In approximately one-half of our recordings, $0.5 \%$ neurobiotin (Vector Laboratories, Burlingame, CA) or biocytin (Sigma, St. Louis, MO) was included in the pipette solution to permit visualization of the recorded neuron. Signals were amplified with an Axoclamp 2B (Axon Instruments, Foster City, CA) followed by a Brownlee model 410 amplifier (Brownlee Precision Co., Santa Clara, CA). They were low-pass-filtered at $1-3 \mathrm{kHz}$ and digitized at twice (or more) the filter cutoff frequency using a National Instruments (Austin, TX) data acquisition board with custom data collection software written in LabVIEW (National Instruments). Membrane potentials were corrected for a liquid junction potential of +5 $\mathrm{mV}$. The drugs used in this study, 4-aminopyridine (4-AP; Research Biochemicals, Natick, MA) and cesium chloride, were bath-applied.

Measurement of electrophysiological parameters. Basic electrophysiological parameters were measured as described by Farries and Perkel (2000a). Because the membrane resistance of many of our recorded neurons varied considerably with membrane potential (as explained by Farries and Perkel, 2000a), the input resistance was not simply calculated from the response of each neuron to a small current pulse delivered at rest. Instead, the input resistance was defined as the maximum slope of the current-voltage curve at membrane potentials more negative than $-50 \mathrm{mV}$. This provides a measure of input resistance that does not depend on what the resting membrane potential of each cell happens to be. The "delay to first action potential" is defined as the time from the onset of a $500 \mathrm{msec}$ depolarizing current pulse to the occurrence of the first action potential (AP) in traces in which only one AP was fired. If no such traces were available in a recording, we made this measurement on traces containing the fewest APs. Other electrophysiological parameters (listed in Table 2) were measured using custom software written in IGOR (WaveMetrics, Lake Oswego, OR), as detailed by Farries and Perkel (2000a).

Anomalous spiny neurons in area $X$. As we describe in Results, we found a spiny neuron (SN) type in area $X$ of the zebra finch that was very similar to the medium spiny type of the mammalian striatum. However, most (132 of 191) spiny neurons recorded in area X of zebra finches exhibited "anomalous" firing properties that distinguished them from mammalian striatal spiny neurons. In particular, these cells fired spikes at the onset of depolarizing current pulses, could only rarely fire more than one or two spikes during a given pulse, and sometimes had unusually broad APs. We believe that these neurons were very likely cells that had been damaged during the slicing process rather than a distinct and novel cell type, because cells like this have been recorded in the mammalian striatum after intracellular dialysis (C. Wilson, personal communication) and because in a few zebra finches almost all recorded cells were of the "healthy" variety. We reasoned that if these anomalous spiny neurons recorded in zebra finches were simply sick, area $\mathrm{X}$ of other songbird species might not be as sensitive to the slicing process and would thus exhibit a lower proportion of such neurons. We tested this idea by recording from area $\mathrm{X}$ in Bengalese finches (Lonchura striata), canaries (Serinus canaria), starlings (Sturnus vulgaris), and a white-crowned sparrow (Zonotrichia leucophrys). In all of those species, the proportion of anomalous spiny neurons was much lower compared with zebra finches: 0 of 8 in a Bengalese finch (one bird), 2 of 17 in canaries (two birds), 4 of 12 in starlings (three birds), and 2 of 4 in a white-crowned sparrow (one bird). We concluded that the anomalous spiny neurons are indeed injured or otherwise altered spiny neurons and excluded them from further analysis. Readers interested in a detailed description of these cells can consult Farries and Perkel (2000a), which describes such neurons recorded from the basal ganglia outside of area $\mathrm{X}$ in zebra finches; these neurons are essentially identical to the ones recorded from area $\mathrm{X}$. A summary of the different cell types recorded from each songbird species is given in Table 1 . We checked for general differences among species by comparing the parameters shown in Table 2 for the SN cell type (the only type common enough to permit comparison); there were no significant differences at the $p=0.05$ level (one-way ANOVA for each of the 10 parameters, using the Bonferroni correction because 10 separate ANOVAs were performed), so the data acquired from different species are combined in all subsequent analyses.

Histology and immunohistochemistry. After recordings were made using neurobiotin or biocytin, slices were immersion-fixed in paraformal- 


\begin{tabular}{|c|c|c|c|c|c|}
\hline & $\begin{array}{l}\text { SN } \\
(92 \text { total })\end{array}$ & $\begin{array}{l}\text { LA } \\
(8 \text { total })\end{array}$ & $\begin{array}{l}\text { LTS } \\
\text { (9 total) }\end{array}$ & $\begin{array}{l}\text { FS } \\
(7 \text { total })\end{array}$ & $\begin{array}{l}\text { AF } \\
\text { (25 total) }\end{array}$ \\
\hline Zebra finch (56 birds) & $\begin{array}{l}59 \text { cells } \\
(36 \text { birds })\end{array}$ & $\begin{array}{l}8 \text { cells } \\
(6 \text { birds })\end{array}$ & $\begin{array}{l}9 \text { cells } \\
\text { (9 birds) }\end{array}$ & $\begin{array}{l}5 \text { cells } \\
(5 \text { birds })\end{array}$ & $\begin{array}{l}20 \text { cells } \\
(15 \text { birds })\end{array}$ \\
\hline Bengalese finch ( 1 bird) & $\begin{array}{l}8 \text { cells } \\
(1 \text { bird })\end{array}$ & 0 & 0 & $\begin{array}{l}1 \text { cell } \\
(1 \text { bird })\end{array}$ & $\begin{array}{l}2 \text { cells } \\
(1 \text { bird })\end{array}$ \\
\hline Canary ( 2 birds) & $\begin{array}{l}15 \text { cells } \\
(2 \text { birds })\end{array}$ & 0 & 0 & $\begin{array}{l}1 \text { cell } \\
(1 \text { bird })\end{array}$ & $\begin{array}{l}1 \text { cell } \\
(1 \text { bird })\end{array}$ \\
\hline Starling ( 2 birds) & $\begin{array}{c}8 \text { cells } \\
(2 \text { birds })\end{array}$ & 0 & 0 & 0 & $\begin{array}{l}1 \text { cell } \\
(1 \text { bird })\end{array}$ \\
\hline $\begin{array}{l}\text { White-crowned sparrow } \\
\text { (1 bird) }\end{array}$ & $\begin{array}{l}2 \text { cells } \\
(1 \text { bird })\end{array}$ & 0 & 0 & 0 & $\begin{array}{l}1 \text { cell } \\
(1 \text { bird })\end{array}$ \\
\hline
\end{tabular}

Table 2. Properties of five cell types identified in area X (mean \pm SD)

\begin{tabular}{|c|c|c|c|c|c|}
\hline & $\begin{array}{l}\mathrm{SN} \\
(n=92)\end{array}$ & $\begin{array}{l}\mathrm{LA} \\
(n=8)\end{array}$ & $\begin{array}{l}\text { LTS } \\
(n=9)\end{array}$ & $\begin{array}{l}\text { FS } \\
(n=7)\end{array}$ & $\begin{array}{l}\mathrm{AF} \\
(n=25)\end{array}$ \\
\hline Resting potential, $\mathrm{mV}$ & $-72 \pm 10^{a}$ & $-51 \pm 8^{f}$ & $-42 \pm 8^{f}$ & $-62 \pm 10$ & NA \\
\hline Input resistance, $\mathrm{M} \Omega$ & $670 \pm 264^{b}$ & $395 \pm 177^{g}$ & $462 \pm 224$ & $452 \pm 509^{f}$ & $232 \pm 112^{j}$ \\
\hline AP threshold, $\mathrm{mV}$ & $-37.7 \pm 5.8^{c}$ & $-43.7 \pm 10.4$ & $-43.5 \pm 8.5$ & $-40.9 \pm 13.6^{f}$ & $-47.7 \pm 6.0$ \\
\hline AP amplitude, $\mathrm{mV}$ & $40.4 \pm 8.0$ & $42.7 \pm 8.9$ & $44.5 \pm 9.6$ & $29.9 \pm 7.8$ & $36.0 \pm 13.5$ \\
\hline AP duration, msec & $1.82 \pm 0.81$ & $2.47 \pm 0.63$ & $1.65 \pm 0.85$ & $0.90 \pm 0.41$ & $0.86 \pm 0.19$ \\
\hline AHP amplitude, $\mathrm{mV}$ & $-13.5 \pm 9.3$ & $-25.3 \pm 6.4$ & $-7.4 \pm 3.8$ & $-13.1 \pm 4.0$ & $-18.7 \pm 5.5$ \\
\hline AHP time to peak, msec & $5.92 \pm 5.69$ & $124.28 \pm 44.78$ & $3.09 \pm 2.1$ & $2.21 \pm 0.89$ & $8.95 \pm 4.88$ \\
\hline Delay to first AP, msec & $339 \pm 105^{d}$ & $207 \pm 132^{f}$ & $65 \pm 45$ & $86 \pm 148^{f}$ & $116 \pm 74^{k}$ \\
\hline Soma diameter, $\mu \mathrm{m}$ & $7.6 \pm 1.1^{e}$ & $19.0 \pm 3.2^{h}$ & $10.7 \pm 2.3^{h}$ & $11.7 \pm 4.2^{i}$ & $11.0 \pm 1.7^{l}$ \\
\hline Soma area, $\mu \mathrm{m}^{2}$ & $43.7 \pm 11.5^{e}$ & $263.6 \pm 84.0^{h}$ & $89.4 \pm 37^{h}$ & $105.9 \pm 68.9^{i}$ & $94.3 \pm 28.4^{l}$ \\
\hline
\end{tabular}

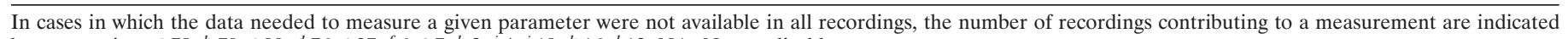
by superscripts: ${ }^{a} 78 ;{ }^{b} 70 ;{ }^{c} 90 ;{ }^{d} 76 ;{ }^{e} 37 ;{ }^{f} 6 ;{ }^{g} 7 ;{ }^{h} 2 ;{ }^{i} 4 ;{ }^{j} 19 ;{ }^{k} 16 ;{ }^{l} 12$. NA, Not applicable.

dehyde ( $4 \%$ in $0.1 \mathrm{M}$ phosphate buffer, for at least $4 \mathrm{hr}$ ) and cryoprotected by immersion in a cold sucrose solution $(30 \%$ in $0.1 \mathrm{M}$ phosphate buffer, for at least $4 \mathrm{hr}$ ). Slices were resectioned to a 30-60 $\mu \mathrm{m}$ thickness with a freezing microtome. Tracer-filled neurons were visualized using an avidin-biotin-horseradish peroxidase complex kit (Vector Laboratories) followed by a reaction with a peroxidase substrate, either diaminobenzidine or the Vector VIP kit (Vector Laboratories). To make morphological measurements, images of filled cells were acquired with a digital camera and measurements were taken with the assistance of imageanalysis software (Global Lab Image; Data Translation Inc., Marlboro, MA). The photomicrographs shown in the figures were acquired with a digital camera, except for those acquired using confocal microscopy (as noted in the figure legends). The images for each cell are montages of several images of that cell taken at different focal planes, to show as much of the neuron in focus as possible. For ChAT immunostaining, sections were incubated overnight in 1:1000 primary antibody ( $\alpha$ ChAT 1465; gift of Dr. M. L. Epstein, University of Wisconsin, Madison, WI) at $4^{\circ} \mathrm{C}$, followed by incubation overnight with $\mathrm{Cy} 5$-conjugated secondary antibody (1:200; Jackson ImmunoResearch, West Grove, PA) at $4^{\circ} \mathrm{C}$. In this ChAT labeling experiment, the intracellular biocytin fill was visualized for fluorescence by incubating slices with Cy2-conjugated streptavidin (Jackson ImmunoResearch); images were acquired with a confocal microscope.

Tracer injection. The medial poriton of the dorsolateral anterior thalamic nucleus (DLM)-projecting area X neuron shown in Figure 14 was labeled by injecting the bidirectional tracer tetramethylrhodamineconjugated dextran (3000 kDa; Molecular Probes, Eugene, OR) into the DLM of an adult male zebra finch. The surgery was performed as described by Luo and Perkel (1999b) and tracer was injected iontophoretically with $5 \mu \mathrm{A}$ pulses (7 $\mathrm{sec}$ on $/ 7 \mathrm{sec}$ off) for $20 \mathrm{~min}$ using a Midgard Precision Current Source (Stoelting Co., Wood Dale, IL). After allowing $5 \mathrm{~d}$ for retrograde transport, the bird was given a lethal overdose of pentobarbital and perfused transcardially with $0.9 \%$ saline followed by $4 \%$ paraformaldehyde (in $0.1 \mathrm{~m}$ phosphate buffer). The brain was removed and cryoprotected by immersion in $30 \%$ sucrose solution (in $0.1 \mathrm{M}$ phosphate buffer) overnight. Brain sections (30 $\mu \mathrm{m}$ thick) were cut using a freezing microtome, mounted on glass slides, and imaged by confocal microscopy.

\section{RESULTS}

\section{The most common cell type in area $X$ closely resembles the principal cell type of the mammalian striatum}

We identified a total of five cell types in area X. The majority of cells we recorded (92 of 141) were small (soma diameter, 5-10 $\mu \mathrm{m}$ ) and possessed moderately to densely spiny dendrites (Fig. $2 C)$; accordingly, we designated this cell type as spiny neuron (SN). On hyperpolarization, these cells always exhibited fast inward rectification (i.e., a rapid decrease in membrane resistance) (Fig. 2A,B). We quantified this inward rectification by calculating the ratio of minimum membrane resistance achieved during hyperpolarization to the input resistance; this ratio was $0.21 \pm 0.17$ (mean $\pm \mathrm{SD} ; n=70$ ). When injected with depolarizing current pulses, all SNs exhibited a characteristic ramping response (Fig. $2 A$ ), ultimately producing APs that were substantially delayed relative to the onset of the current pulse for sufficiently large current levels (Fig. 3). As larger current pulses were delivered, these cells fired at higher rates (Fig. 3B) and with a shorter delay from the onset of the pulse to the first spike (Fig. $3 C$ ); some spike-rate accommodation was present (Fig. 3D). SNs did not fire spontaneously. Physiological and morphological measurements for SNs and all other cell types are given in Table 2; Table 3 summarizes the significant differences among them.

The SNs we recorded in area $\mathrm{X}$ were remarkably similar to the 

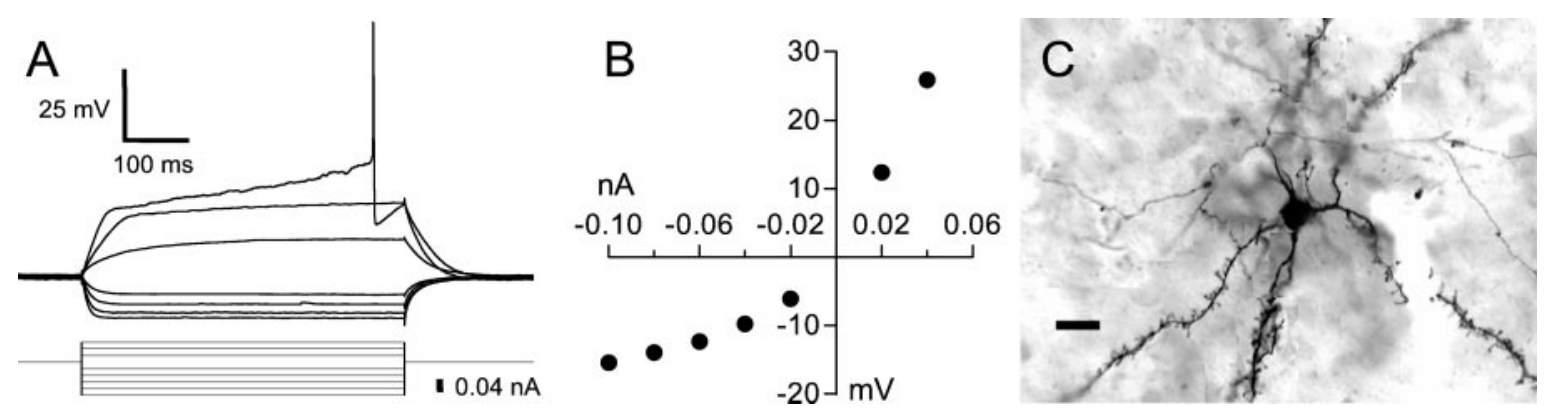

Figure 2. Intrinsic properties of the SN cell type. $A$, Response of a $\mathrm{SN}$ to a series of hyperpolarizing and depolarizing current pulses. The baseline potential was $-82 \mathrm{mV}$. B, Graph of the steady-state voltage deflection in this neuron as a function of current pulse amplitude. $C$, Photomicrograph of the neuron shown in $A$ and $B$, filled with biocytin. This photomicrograph, like all others in this paper except the confocal images, is a montage of several images of this cell taken at different focal planes to show as much of the cell in focus as possible. Scale bar, $10 \mu \mathrm{m}$. This cell was recorded in a canary brain slice.

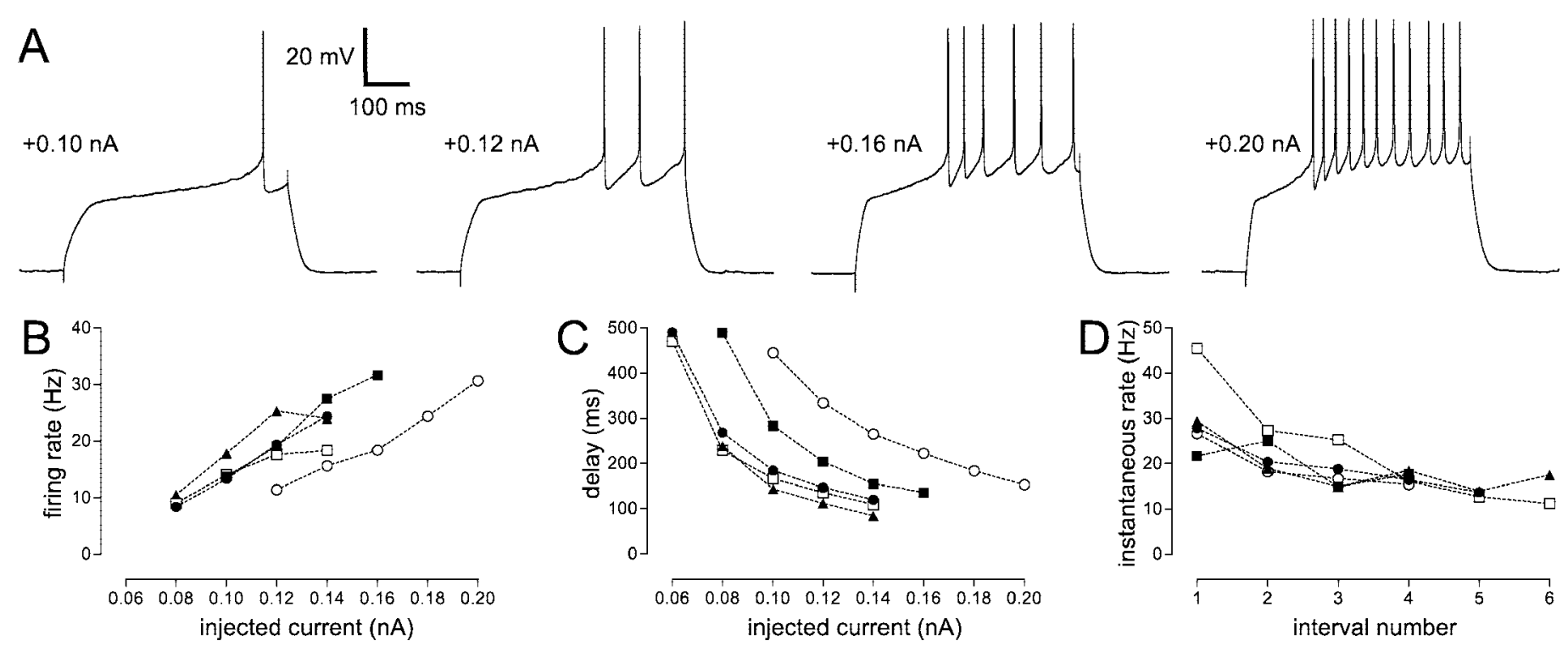

Figure 3. Firing properties of the SN cell type. A, Sample traces of an SN firing in response to four successively larger 500 msec current pulses. The baseline potential was $-84 \mathrm{mV}$. $B$, Firing rate plotted as a function of injected current for five representative SNs. The firing rate was defined as the inverse of the average interspike interval, so that the delay before the first spike is excluded from this calculation. Each symbol corresponds to a different neuron, and a given symbol represents the same neuron in $B-D$ (e.g., the filled circles signify the same cell in all panels). $C$, Delay from the onset of the current pulse to the time of the first spike for the same five SNs, plotted as a function of current amplitude. $D$, Spike rate accommodation for these SNs, illustrated by plotting the instantaneous firing rate (inverse of the interspike interval) for each interval during a current pulse that evoked a mean firing rate of $\sim 20 \mathrm{~Hz}$. Current pulse amplitude for each neuron: filled circle, $0.12 \mathrm{nA}$; filled square, $0.12 \mathrm{nA}$; filled triangle, $0.10 \mathrm{nA}$; open circle, $0.16 \mathrm{nA}$; open square, $0.14 \mathrm{nA}$. Each point in these graphs represents the average of two repetitions of the same current amplitude. All current pulses were 500 msec in duration. The sample traces shown in $A$ were taken from the neuron denoted by open circles in $B-D$. The cells denoted by filled circles and open squares were recorded in canary brain slices; the others are from zebra finches.

principal cell type of the mammalian striatum, the medium spiny neuron (MSN). They share two characteristic properties: fast inward rectification on hyperpolarization and a ramping response to depolarizing current (Kita et al., 1984; Jiang and North, 1991; Nisenbaum and Wilson, 1995). In mammals, the fast inward rectification is blocked by $\mathrm{Cs}^{+}$, whereas the ramping response is eliminated by 4-AP, a blocker of A-type $\mathrm{K}^{+}$channels (Nisenbaum et al., 1994; Nisenbaum and Wilson, 1995). We further examined the physiological similarities between area $X$ and the mammalian striatum by examining the effect of these channel blockers on area X SNs. Bath application of $100 \mu \mathrm{M}$ 4-AP eliminated the ramping response and the delayed spiking in SNs (Fig. $4 A)(n=12$; delay to first spike went from $421 \pm 56 \mathrm{msec}$ to $181 \pm 94 \mathrm{msec}$ on application of 4-AP; $p<0.0001$, paired $t$ test), just as it does in mammalian MSNs. Bath application of $3 \mathrm{~mm}$ $\mathrm{CsCl}$ abolished the fast inward rectification (Fig. $4 B)(n=4$; the inward rectification ratio went from $0.18 \pm 0.13$ to $1.00 \pm 0.00$ on application of $\mathrm{CsCl} ; p=0.001$, paired $t$ test) and usually revealed outward rectification in response to hyperpolarizing current (data not shown), an effect that has also been observed in mammalian MSNs (Uchimura et al., 1989; Belleau and Warren, 2000). Our experiments did not find any qualitative electrophysiological or morphological difference between the spiny neurons of area $\mathrm{X}$ and those of mammalian striatum.

\section{Presumptively cholinergic neurons in area $X$ resemble the cholinergic interneurons of mammalian striatum}

All of the other cell types we found in area X had aspiny or sparsely spiny dendrites and had substantially larger somata than the SNs. One such cell type exhibited a characteristically longduration afterhyperpolarization (AHP) after each AP and are named "long-lasting afterhyperpolarization" (LA) neurons (Fig. 


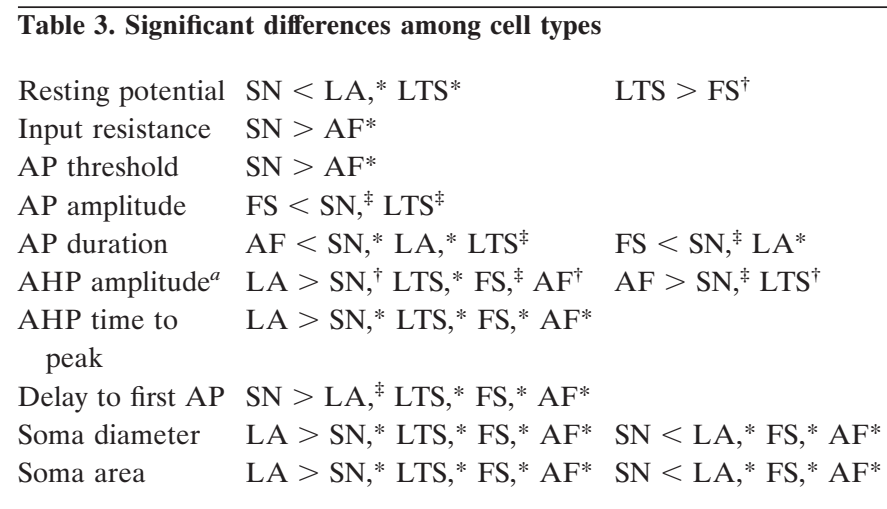

Comparisons for a given parameter are shown as follows: $x<y, z$ indicates that the mean value of that parameter for cell type $x$ is significantly less than that of cell types $y$ and $z$. Differences were identified by one-way ANOVA for each parameter followed by Tukey's post hoc comparison if the means were found to be different at the $p=0.05$ level. Significance levels: ${ }^{*} p<0.001 ;{ }^{\dagger} p<0.01 ;{ }^{\ddagger} p<0.05$.

${ }^{a}$ AHP amplitude is compared by absolute value (e.g., $-10 \mathrm{mV}$ is "bigger" than $-5 \mathrm{mV})$.
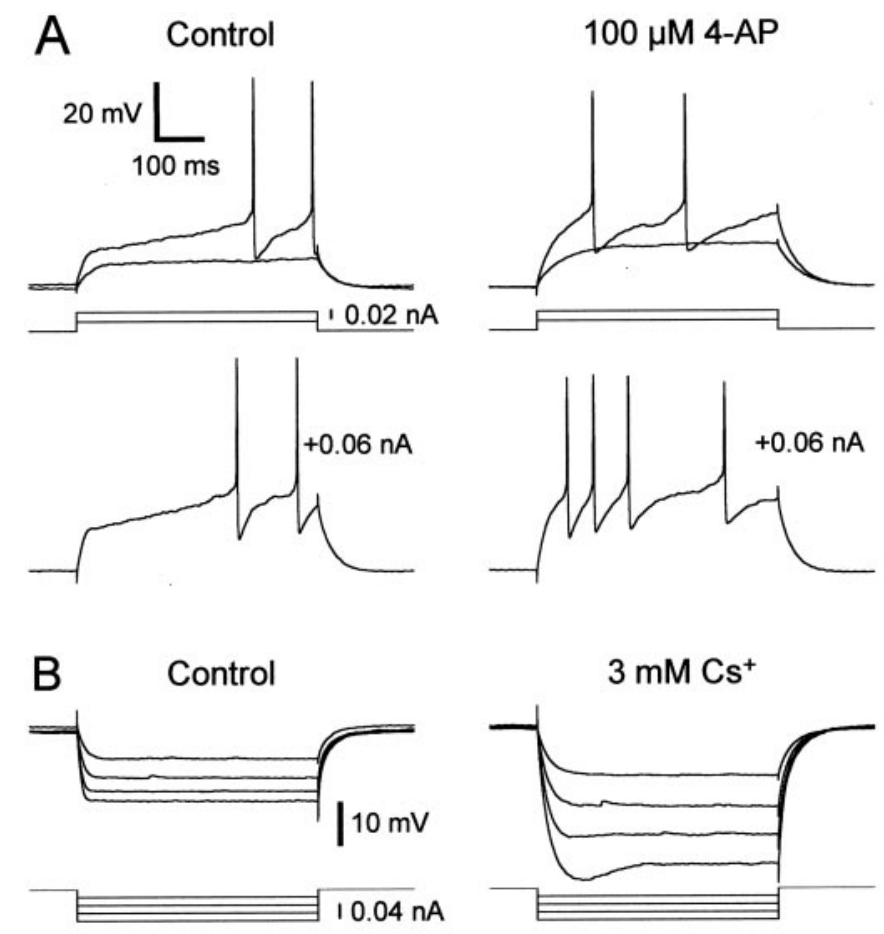

Figure 4. 4-AP-sensitive and cesium-sensitive conductances in SNs. $A$, 4-AP eliminates the ramping response and delayed spiking in SNs. Left, Response of an SN to three successively larger depolarizing current pulses before drug application. Right, Response of this SN to the same current pulses after bath application of $100 \mu \mathrm{M}$ 4-AP. The baseline membrane potential was $-80 \mathrm{mV}$. $B$, Cesium blocks the fast inward rectification exhibited by SNs. Left, Response of an SN to a series of hyperpolarizing current pulses before drug application. Right, Response of this SN to the same current pulses after bath application of CsCl. The baseline membrane potential was $-74 \mathrm{mV}$. Both of these neurons were recorded in zebra finch brain slices.

5). These cells fired spontaneously at low rates (five of eight cells at $0.7 \pm 0.2 \mathrm{~Hz}$ ) or exhibited slow membrane potential fluctuations without spiking (Fig. $6 \mathrm{~A}$ ); they generally did not rest at a stable membrane potential (the "resting potential" given in Table 2 was measured at times when these cells were more quiescent and should be interpreted loosely). These cells often (five of eight) exhibited time-dependent inward rectification in response to hyperpolarizing current pulses (seen as a sag in membrane potential during the pulse), followed by rebound depolarization or spiking (Fig. 6B). When injected with depolarizing current pulses, they fired repetitively (Fig. $6 D$ ), but none of our recorded LA neurons could sustain firing at rates of $>10 \mathrm{~Hz}$. Instead, a larger depolarizing current would evoke only one or two spikes at the beginning of the pulse (Fig. 6C).

The LA neurons of area $\mathrm{X}$ bear a striking resemblance to a cell type of the same name identified in the mammalian striatum. Both types have unusually long afterhyperpolarizations (Kawaguchi, 1992, 1993), can be spontaneously active in vitro at comparable rates (Bennett and Wilson, 1999), and show a sagging response to hyperpolarization that is followed by rebound depolarization (Kawaguchi, 1992, 1993). The LA neurons of the mammalian striatum contain ChAT, the enzyme that synthesizes acetylcholine (Kawaguchi, 1993). Naturally, we wondered whether the LA neurons of area X contain ChAT, and in one case we were able to process a filled LA neuron for ChAT immunohistochemistry. This neuron proved to be ChAT-positive (Fig. 7). The LA neurons of area $\mathrm{X}$ are physiologically and histochemically very similar to their counterparts in the mammalian striatum; the few differences we did observe (lesser capacity for repetitive firing, less prominent time-dependent inward rectification) could have been attributable to differences in recording conditions or the state of our brain slices.

\section{Low-threshold spike cell type in area $X$}

A second large, aspiny cell type we observed in area $\mathrm{X}$ fired a broad, plateau-like AP when injected with a depolarizing current from a hyperpolarized baseline potential (Fig. 8); we call these neurons "low-threshold spike" (LTS) cells. LTS cells rested at relatively depolarized potentials (Table 2) or in some cases spontaneously fired bursts of APs (three of nine cells) (Fig. 9A). When injected with hyperpolarizing current pulses, LTS cells displayed a sagging response indicative of time-dependent inward rectification (Fig. $8 A, B$ ). A depolarizing rebound followed the termination of hyperpolarizing current pulses, which triggered APs in some cases (Fig. 9B). The plateau-like spike of LTS cells was triggered at a relatively negative threshold potential: $-57 \pm 5$ $\mathrm{mV}$. This plateau-like spike was accompanied by a few conventional fast APs restricted to the early peak of the plateau (Fig. $8 \mathrm{~A}$ ), but in one cell spiking continued at a lower rate throughout the injected current pulse (Fig. $9 C$ ). The plateau generally could be evoked only if the cell was first hyperpolarized (Fig. 9D), which is not surprising in light of the fact that these neurons invariably rested at potentials more depolarized than the threshold for the plateau-like spike.

The LTS cell type of area X, like the SN and LA cell types, strongly resembles its counterpart in the mammalian striatum. This mammalian cell type, known as the LTS or "persistent low-threshold spike" (PLTS) interneuron class, fires plateau-like spikes, exhibits a sagging response to hyperpolarization that can be followed by rebound spikes, and fires fast APs near the beginning of the plateau (Kawaguchi, 1993; Kubota and Kawaguchi, 2000), just as in the LTS neurons of area X. There is some heterogeneity in the firing properties of the LTS/PLTS cell type in mammals (Koós and Tepper, 1999), which also appears among our recorded LTS neurons (specifically, the sustained firing evident in the cell shown in Fig. 9B). 


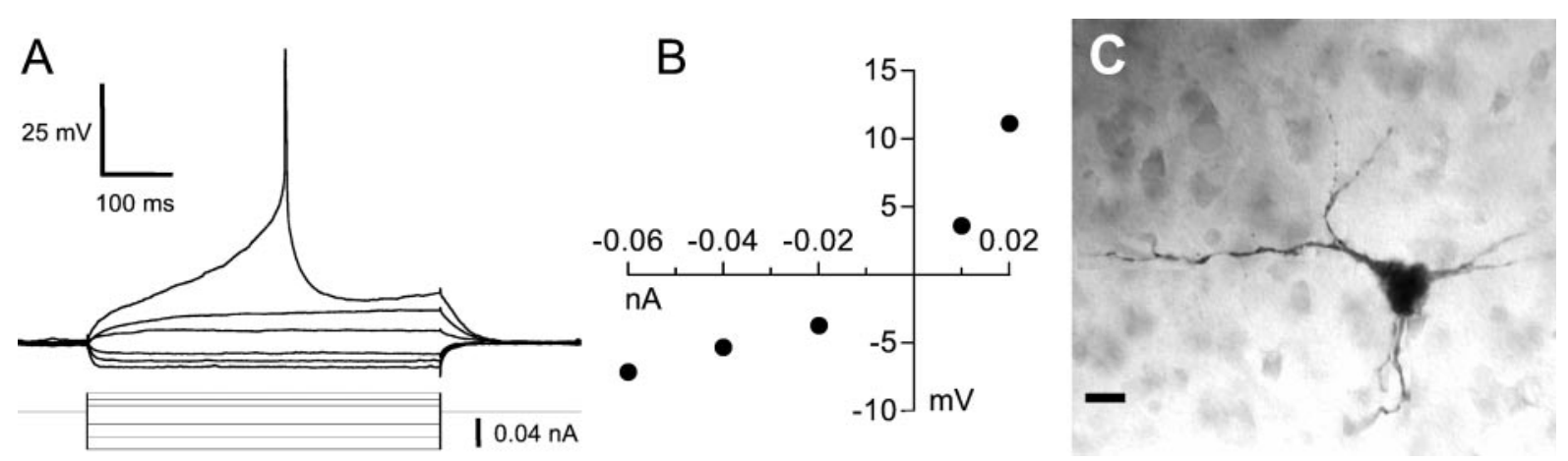

Figure 5. Intrinsic properties of the LA cell type. $A$, Response of an LA neuron to a series of hyperpolarizing and depolarizing current pulses. These current pulses were delivered from a hyperpolarized potential of $-90 \mathrm{mV}$, maintained by continuous injection of $-0.16 \mathrm{nA}$. $B$, Graph of the steady-state voltage deflections in this neuron as a function of current pulse amplitude. $C$, Photomicrograph of the neuron $\operatorname{shown}$ in $A$ and $B$, filled with neurobiotin. Scale bar, $10 \mu \mathrm{m}$. This neuron was recorded in a zebra finch brain slice.
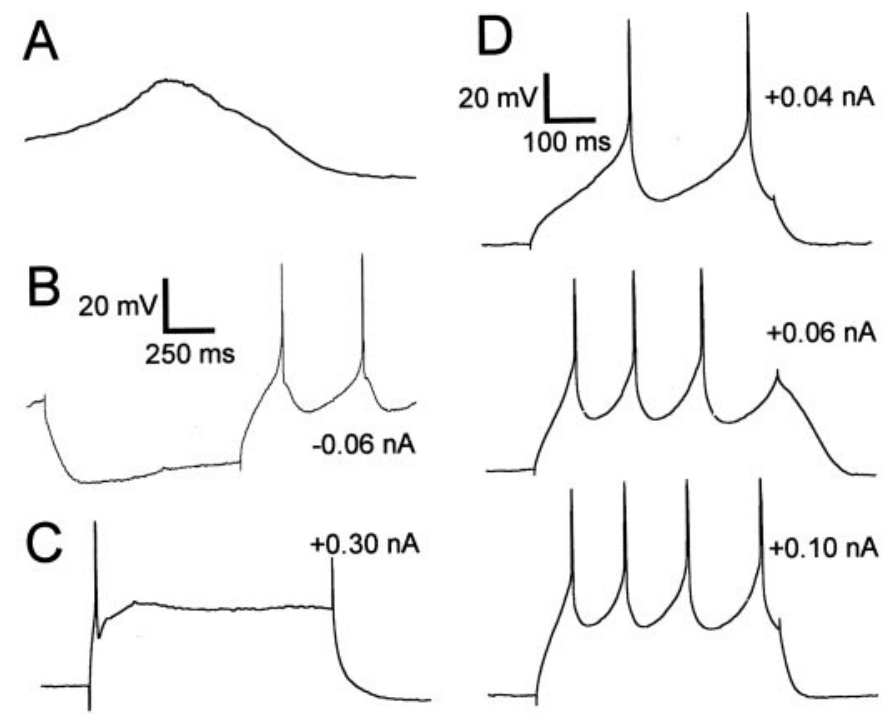

Figure 6. Firing properties of the cholinergic LA cell type. A, A spontaneous depolarizing event recorded in an LA neuron (recorded from a zebra finch); the cell would normally fire a fast AP at the crest of this event. The membrane potential at the beginning of the trace was $-65 \mathrm{mV}$. The calibration is shown in $D . B$, Response of a different LA neuron to a hyperpolarizing current pulse during ongoing spontaneous activity, showing a sagging response. The spontaneous firing rate was momentarily elevated after the current pulse. The baseline potential was $-54 \mathrm{mV}$. $C$, Response of an LA neuron to a $+0.3 \mathrm{nA}$ current pulse; the LA is no longer apparent. (This is the same cell shown in Fig. 7.) The baseline potential is $-61 \mathrm{mV}$. The calibration is shown in $D$. $D$, Sample traces of an LA neuron firing in response to three successively larger $500 \mathrm{msec}$ current pulses. (This is the same cell shown in Fig. 5.) The amplitudes of the current pulses are indicated to the right of each trace. These current pulses were delivered from a hyperpolarized potential of $-90 \mathrm{mV}$, maintained by continuous injection of $-0.16 \mathrm{nA}$.

\section{Fast-spiking cell type in area $X$}

Two physiological classes of GABAergic interneuron are known in the mammalian striatum: the LTS/PLTS class discussed above and a fast-spiking (FS) class (Kawaguchi, 1993; Kubota and Kawaguchi, 2000). Area $X$ also has an FS cell type. These cells were significantly larger than SNs and possessed aspiny or sparsely spiny dendrites (Fig. 10C). They did not fire spontaneously, and exhibited varying degrees of fast inward rectification when hyperpolarized (Fig. 10 $A, D$ ) (minimum resistance to input resistance ratio, $0.45 \pm 0.35$; range, 0.12-0.93). When injected with depolarizing current pulses, FS neurons sometimes gave a ramping response (much briefer than that seen in SNs; arrow in Fig. 10D) coincident with or followed by intermittent spiking. FS cells characteristically fired APs in bursts interspersed with silent intervals containing small oscillations in membrane potential (Fig. $11 A, B$ ). With increasing current injections, each burst contained more APs (Fig. $11 A$ ) fired at higher intraburst rates (Fig. 11C, open circles) and with shorter intervals between bursts, until above a certain current level the neuron fired continuously at very high rates (Fig. $11 \mathrm{~A}$, bottom). In all these respects, the FS neurons in area $\mathrm{X}$ were virtually identical to mammalian striatal FS cells, save only that the FS cells we recorded rested at more depolarized membrane potentials (Kawaguchi, 1993; Koós and Tepper, 1999).

\section{The aspiny, fast-firing cell type of area $X$ resembles a cell type found in the mammalian globus pallidus}

The four cell types described above account for all of the major physiological classes identified in the mammalian striatum to date. However, we did find a fifth physiological cell type in area $\mathrm{X}$ that has never been reported in the mammalian striatum. These neurons are most clearly distinguished from the other four types by their propensity to fire APs spontaneously at a relatively high rate $(18.4 \pm 11.6 \mathrm{~Hz})($ Fig. 12A). Morphologically, these cells were not unlike the FS cell type, possessing a relatively large soma surrounded by thin, beaded, highly branched neurites (Fig. 12D). We call this the aspiny, fast-firing (AF) cell type.

To study the current-voltage relationship in these neurons, we silenced their spontaneous activity by continuously injecting hyperpolarizing current, holding them at a baseline potential of approximately $-75 \mathrm{mV}$. Hyperpolarizing current pulses evoked a sagging response, followed by a depolarizing rebound after the pulse, whereas subthreshold depolarizing pulses produced a depolarizing hump near the onset of the pulse followed by a small hyperpolarization after its termination (Fig. 12B,C). Hyperpolarizing pulses could trigger a rebound burst (Fig. 13C) and hyperpolarizing pulses delivered during spontaneous firing were succeeded by a transient increase in the firing rate relative to baseline (Fig. 13D). When depolarizing pulses (delivered from a hyperpolarized baseline) were large enough to trigger APs, the spike rate was typically highest early in the pulse and declined to a slower, steady rate thereafter (Figs. 12 $A, 13$ ). The firing rate increased roughly linearly with current amplitude (Fig. 13B) and AF cells could sustain firing at very high rates, sometimes exceeding $100 \mathrm{~Hz}$ (Fig. 13A).

Although AF neurons did not resemble any cell type identified in the mammalian striatum, they closely resemble some neurons 

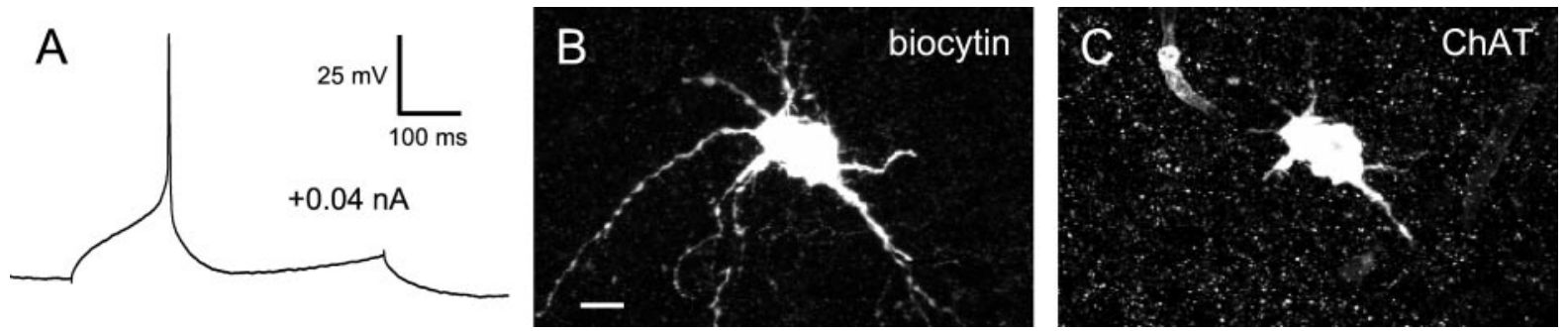

Figure 7. ChAT immunoreactivity in an LA neuron. $A$, Spike evoked in an LA neuron, showing the characteristic long-lasting afterhyperpolarization. The baseline potential was $-64 \mathrm{mV}$, maintained by continuous injection of $-0.04 \mathrm{nA}$. B, Biocytin fill of this neuron, visualized with Cy2-conjugated streptavidin and acquired with a confocal microscope. Scale bar, $25 \mu \mathrm{m}$. $C$, ChAT immunostaining in this neuron visualized with a Cy5-conjugated secondary antibody, suggesting that it is cholinergic. This neuron was recorded from a zebra finch brain slice.
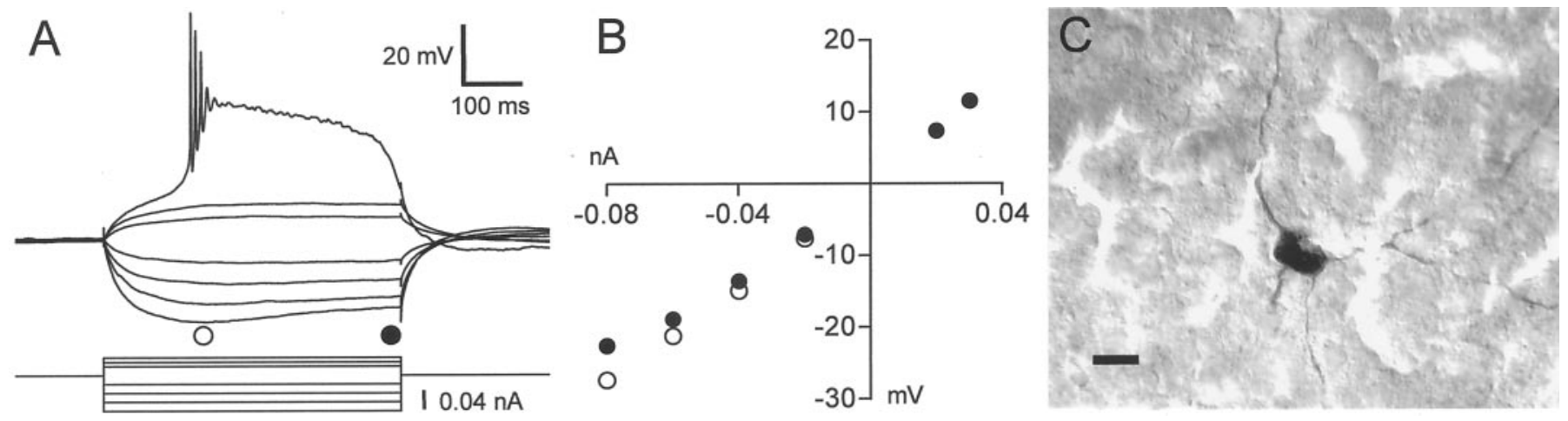

Figure 8. Intrinsic properties of the LTS cell type. A, Response of an LTS neuron to a series of hyperpolarizing and depolarizing current pulses. These current pulses were delivered from a hyperpolarized potential of $-76 \mathrm{mV}$, maintained by the continuous injection of $-0.06 \mathrm{nA}$. $B$, Graph of the steady-state voltage deflections in this neuron as a function of current pulse amplitude. Filled circles, Voltage deflection at the end of the current pulse; open circles, voltage deflection earlier in the current pulse, near the bottom of the "sag" (time of measurement indicated by the position of the circles below the voltage traces in $A$ ). $C$, Photomicrograph of the neuron shown in $A$ and $B$, filled with neurobiotin. Scale bar, $10 \mu \mathrm{m}$. This neuron was recorded in a zebra finch brain slice.

recorded from the mammalian globus pallidus. One cell type identified in the rat entopeduncular nucleus (equivalent to the internal segment of the globus pallidus of primates) shares all of the major physiological features of AF cells: They fire spontaneously in vitro, exhibit time-dependent inward rectification, produce depolarizing "bumps" near the onset of depolarizing current pulses, are capable of sustained firing at high rates, and display rebound firing after hyperpolarizing current pulses (Nakanishi et al., 1990). A cell type recorded from the rat ventral pallidum in vitro also shares most of these features (Bengtson and Osborne, 2000).

Because both the entopeduncular nucleus (internal globus pallidus) and ventral pallidum project to the thalamus in mammals (Zahm et al., 1987; Parent and Hazrati, 1995), we suspect that the AF cells are the projection neurons of area $\mathrm{X}$, which innervate the thalamic nucleus DLM. Unfortunately, we did not observe an axon leaving area $X$ in any of our tracer-filled neurons, so we have no direct evidence that identifies the projection neurons. Nevertheless, circumstantial evidence based on cell morphology strongly suggests that the projection neurons of area $\mathrm{X}$ belong to the AF class. From retrograde tracing experiments, we know that the neurons projecting to DLM are larger than the majority of area $\mathrm{X}$ neurons, contain glutamic acid decarboxylase (the enzyme that synthesizes GABA), and possess thin, beaded neurites with few if any dendritic spines (Luo and Perkel, 1999b). SNs cannot be the projection neurons because they have densely spiny dendrites and have the smallest somata of the neurons we recorded. The LA neurons also appear morphologically distinct from the

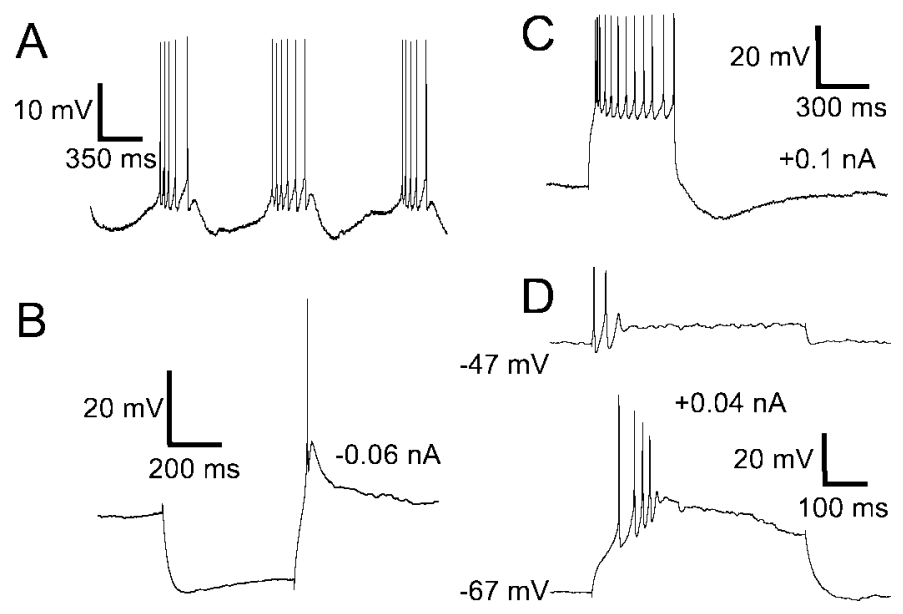

Figure 9. Firing properties of the LTS cell type. $A$, Example of spontaneous activity in an LTS neuron; this neuron exhibited the highest rate of spontaneous activity of any LTS neuron we recorded. $B$, Rebound spike fired after a hyperpolarizing current pulse delivered from rest. The baseline potential was $-60 \mathrm{mV}$. $C$, An example of an LTS neuron that could fire APs throughout a depolarizing current pulse. The baseline potential was $-69 \mathrm{mV}$, maintained by continuous injection of $-0.02 \mathrm{nA}$. This cell is the same as the one shown in $A$. $D$, APs evoked in an LTS cell by a current pulse delivered from rest (top, baseline potential of $-47 \mathrm{mV}$ ) and a hyperpolarized potential (bottom, baseline potential of $-67 \mathrm{mV}$ maintained by continuous injection of $-0.06 \mathrm{nA}$ ). All of the cells in this figure were recorded in zebra finch brain slices. 

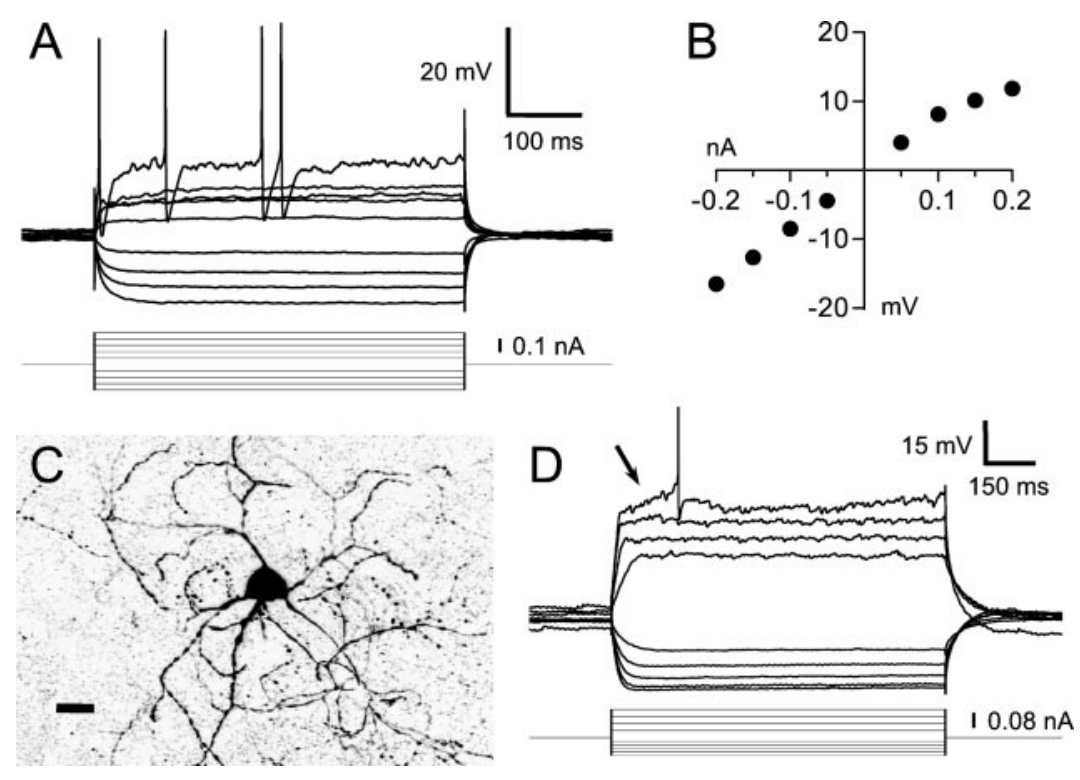

Figure 10. Intrinsic properties of the FS cell type. $A, \mathrm{Re}-$ sponse of an FS neuron to a series of hyperpolarizing and depolarizing current pulses. The baseline potential was -55 $\mathrm{mV} . B$, Graph of the steady-state voltage deflections in this neuron as a function of current pulse amplitude. $C$, Confocal image of the neuron shown in $A$ and $B$, filled with biocytin. Scale bar, $25 \mu \mathrm{m}$. $D$, Response of a different FS neuron to current pulses (delivered from a potential of -75 $\mathrm{mV}$ maintained by continuous injection of $-0.02 \mathrm{nA}$ ). This panel illustrates two common properties of FS neurons not clearly visible in $A$ : a brief ramping response to depolarization (arrow) and fast inward rectification on hyperpolarization. Both neurons in this figure were recorded in zebra finch brain slices.
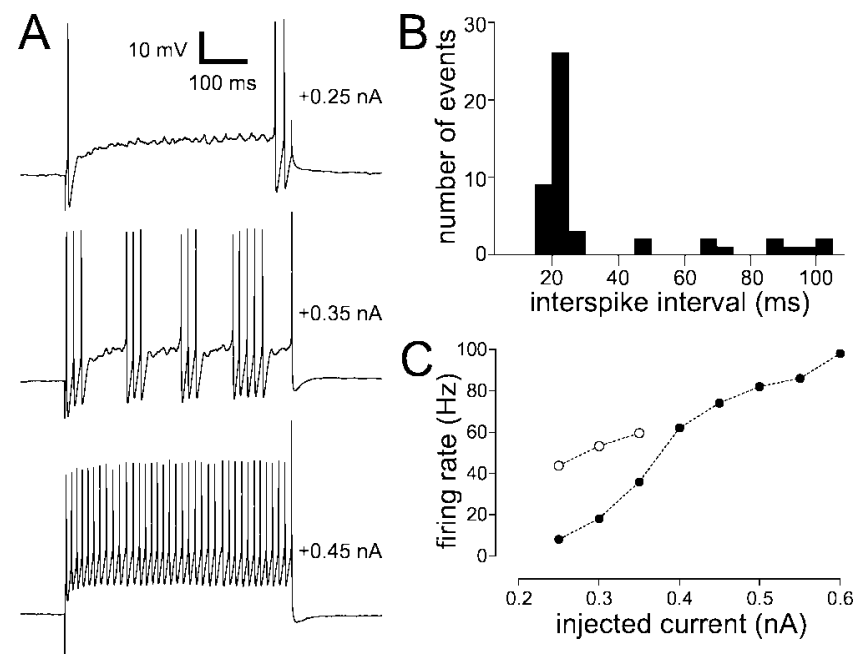

Figure 11. Firing properties of the FS cell type. The cell depicted here is the same as that in Figure $10 A-C$. $A$, Sample traces of this cell firing in response to three successively larger $500 \mathrm{msec}$ current pulses. The amplitudes of the current pulses are indicated to the right of each trace. For moderate current amplitudes, the cell fired intermittently. The baseline potential was $-55 \mathrm{mV}$. $B$, Histogram of interspike intervals for this cell during $+0.35 \mathrm{nA}$ current pulses (three repetitions). This shows two populations of interspike intervals: short $(<30 \mathrm{msec})$ intraburst intervals and longer ( $>40 \mathrm{msec}$ ) interburst intervals ("pauses"). $C$, Firing rate of this cell as a function of injected current. Filled circles show the firing rate averaged over the entire current pulse; open circles show the firing rate during current levels that evoked intermittent firing, excluding the pauses. This rate was defined as the inverse of the intraburst interspike interval (i.e., excluding intervals that were $>40 \mathrm{msec}$ ). These points were an average of one to three repetitions of each current pulse.

projection neurons; although we recovered only two tracer-filled LA cells, they were markedly larger than the projection neurons described by Luo and Perkel (1999b) and have thicker, unbeaded dendrites. The LTS cells are unlikely to be the projection neurons because their dendrites are unbeaded and relatively unbranching, although again we have only two filled LTS cells on which to base this observation. Only the FS and AF cell types morphologically resemble the DLM-projecting neurons of area X (Fig. 14 shows a comparison of an AF cell with a DLM-projecting neuron). Be- cause FS cells closely resemble a mammalian striatal cell type believed to be interneuronal, we think that the AF cells are most likely to be the projection neurons of area X.

\section{Unclassified cells recorded in area $X$}

We recorded seven neurons in area $X$ that could not be clearly classified into one of the above cell types $(<5 \%$ of all stable recordings). All of these recordings exhibited similarities to one or another of the basic cell types but did not last long enough to be fully tested or differed from their apparent cell type in an important respect. Three of these neurons resembled the FS type in that they had short AP durations $(0.52,0.47$, and $0.58 \mathrm{msec}$ ) and were not spontaneously active, but their firing properties were not explored sufficiently to permit confident identification. Three other neurons resembled the LTS cell type but had recordings that were too brief to examine their properties fully or were obscured by massive spontaneous synaptic input. A seventh cell closely resembled the LA type but exhibited the characteristic long-lasting AHP only on the first AP of spike trains evoked by depolarizing current injection. The subsequent APs consistently lacked this long-lasting AHP; consequently, this cell cannot be unambiguously classified as LA.

\section{The basic properties of area $X$ neurons do not change during the period of song development}

Neurons in some regions of the song system undergo changes in their physiological properties during the period of song development (Livingston and Mooney, 1997; Boettiger and Doupe, 1998; Bottjer et al., 1998; Stark and Perkel, 1999; White et al., 1999). Because we recorded from area $\mathrm{X}$ neurons of the zebra finch at a variety of ages, we were able to look for such developmental changes in area $\mathrm{X}$. We did not observe any qualitative changes in any of the cell types we identified, so we looked for quantitative changes in a variety of parameters (all of the measurements listed in Table 2). We focused on SN and AF cells recorded from zebra finches, because all of our juvenile recordings were from zebra finches, and only SN and AF cells were common enough to permit a meaningful comparison. We checked for age-related changes in two ways. First, we divided our zebra finch recordings into two groups, juveniles ( $<65 \mathrm{~d}$ old) and adults ( $\geq 80 \mathrm{~d}$ old), and tested for significant differences between the two groups in any of the 
Figure 12. Intrinsic properties of the AF cell type. $A$, Spontaneous activity recorded in an AF neuron; calibration is the same as in $B . B$, Response of this neuron to a series of hyperpolarizing and depolarizing current pulses. These current pulses were delivered from a hyperpolarized potential of $-75 \mathrm{mV}$, maintained by the continuous injection of $-0.06 \mathrm{nA}$. $C$, Graph of the steady-state voltage deflections in this neuron as a function of current pulse amplitude. Filled circles, Voltage deflection at the end of the current pulse; open circles, voltage deflection earlier in the current pulse, near the bottom of the sag (time of measurement indicated by the position of the circles below the voltage traces in $A$ ). $D$, Photomicrograph of the neuron shown in $A-C$, filled with neurobiotin. Scale bar, $10 \mu \mathrm{m}$. This neuron was recorded in a zebra finch brain slice.
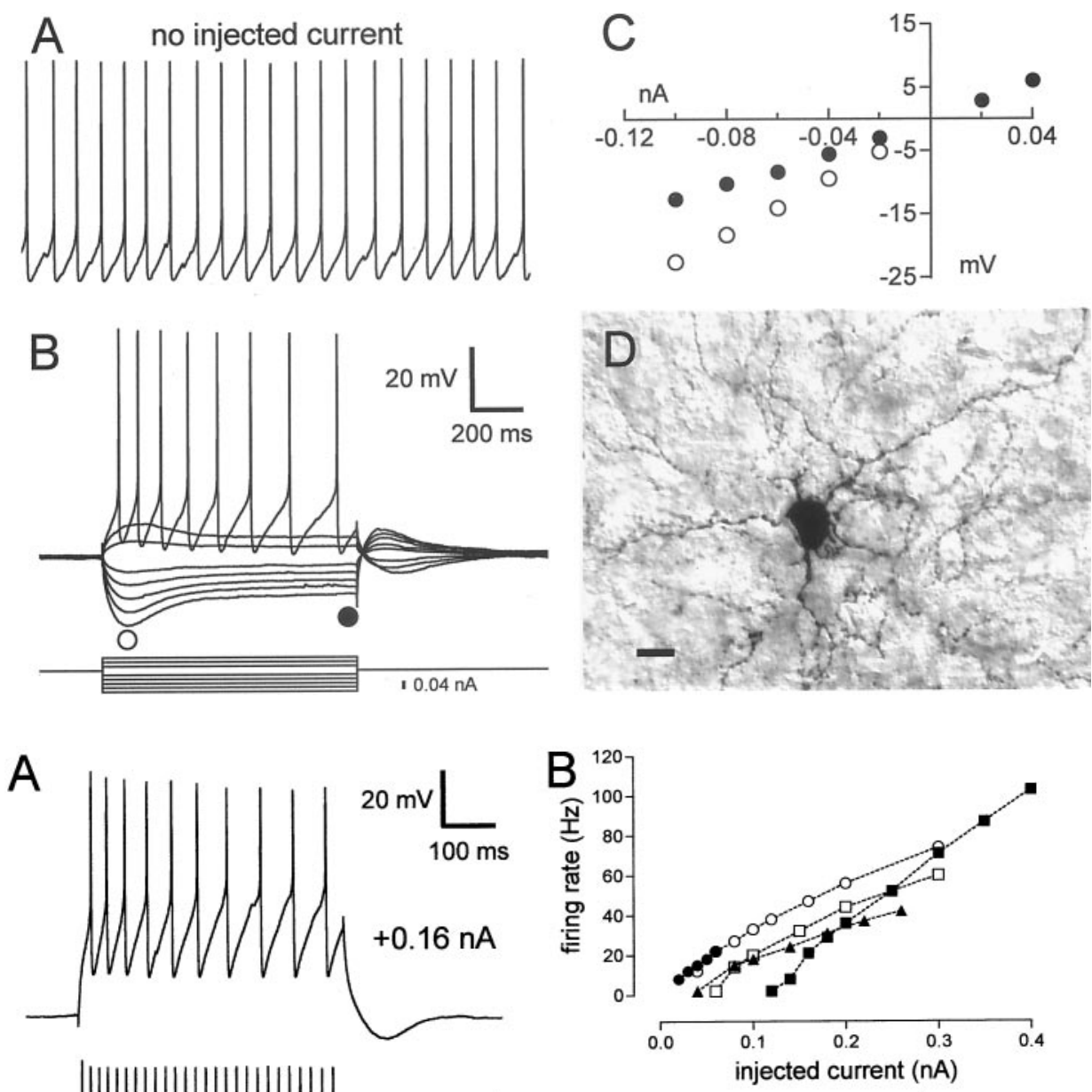

Figure 13. Firing properties of the AF cell type. $A$, Sample traces of this cell spiking in response to three successively larger $500 \mathrm{msec}$ current pulses. The amplitudes of the current pulses are indicated to the right of each trace. Spontaneous activity was silenced by the continuous injection of $-0.19 \mathrm{nA}$. The baseline potential was $-75 \mathrm{mV}$. $B$, Firing rate plotted as a function of injected current for five representative $\mathrm{AF}$ cells. The sample traces shown in $A$ were taken from the neuron denoted by a filled square. $C$, Rebound firing evoked in an AF cell by a hyperpolarizing current pulse. Spontaneous activity was silenced by the continuous injection of -0.06 $\mathrm{nA}$; the baseline potential was $-70 \mathrm{mV} . D$, Response of an AF cell to a hyperpolarizing current pulse delivered during ongoing spontaneous activity. The spontaneous firing rate was briefly elevated immediately after the termination of the pulse.
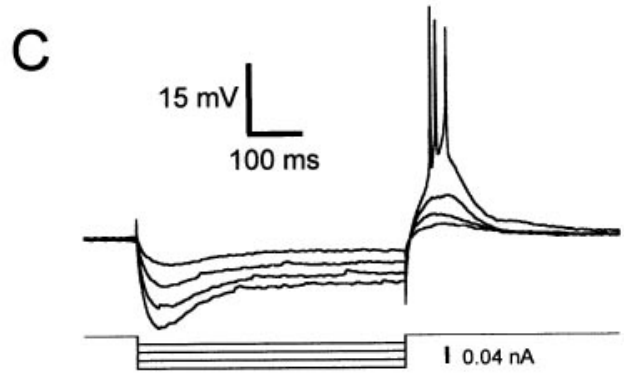

D

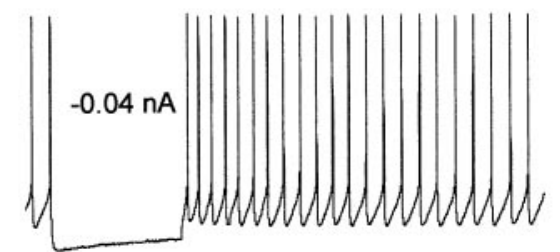

parameters listed in Table 2. In the juvenile group there were 23 SNs (from birds aged 30-57 d; mean, 45) and 10 AF cells (from birds aged 31-61 d; mean, 51). Among adults, there were 30 SNs and 9 AF cells. We found no significant differences at the $p=0.05$ level ( $t$ test with the Bonferroni correction for multiple comparisons). We also tried to detect age-related changes by performing a linear regression on age for each measured parameter, using only cells recorded from birds raised in our colony (the only birds for which we have precise knowledge of age; this includes all birds in the aforementioned juvenile group plus some older birds). For all parameters, the regression slopes were not significantly differ- ent from zero. In summary, we did not observe any physiological or morphological changes in area $\mathrm{X}$ neurons over the age range during which song normally develops in zebra finches. This is consistent with the electrophysiological maturation process observed in the mammalian striatum, which in rats and cats is generally complete by postnatal day 30 (Cepeda et al., 1991; Belleau and Warren, 2000). However, it is important to note that many developmental neurophysiological changes reported in the song system concern synaptic properties (Livingston and Mooney, 1997; Stark and Perkel, 1999; White et al., 1999), which were not examined in this study. 

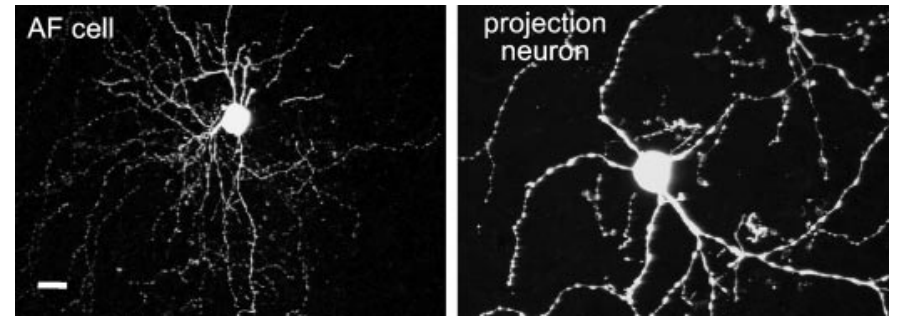

Figure 14. The morphological similarity between AF cells and the DLM-projecting cells of area X. The AF cell was recorded via the whole-cell method from a zebra finch brain slice and filled with biocytin; the area $\mathrm{X}$ projection neuron was labeled by injection of a retrogradely transported tracer (tetramethylrhodamine-conjugated dextran) into the DLM of a different male zebra finch. Both images were acquired with a confocal microscope (the biocytin fill was visualized using Cy2-conjugated streptavidin) and are shown at the same scale. Scale bar, $10 \mu \mathrm{m}$.

\section{DISCUSSION}

The basal ganglia of birds and mammals share a remarkable number of anatomical (Medina and Reiner, 1995) and electrophysiological (Farries and Perkel, 2000a) traits, despite the apparent differences in the organization of their telencephala. Here, we have shown that the electrophysiological similarities extend to area $\mathrm{X}$, a nucleus embedded within the songbird striatum that is specialized for song-related functions. All of the major physiological cell types (SN, LA, LTS, and FS) identified in the mammalian striatum are present in area $\mathrm{X}$. These neurons are surprisingly similar to their mammalian counterparts, given that the last common ancestor of mammals and birds lived at least 290 million years ago (Kardong, 1998), not to mention the fact that song system nuclei are often assumed to be highly specialized within the avian brain. We did not directly test the neurochemical phenotype of our recorded neurons, except in the case of the single ChAT-positive LA cell, but we have reason to believe that the close resemblance to mammals applies here as well. The SNs of area $\mathrm{X}$ are very likely to be GABAergic, like their mammalian counterparts, because area $X$ neurons of the same size range as our recorded SNs are known to contain glutamic acid decarboxylase (Luo and Perkel, 1999b). Mammalian striatal LTS and FS cell types contain nitric oxide synthase and parvalbumin, respectively (Kawaguchi, 1993); their counterparts in area X may contain these proteins as well, given that both are present in area $\mathrm{X}$ (Wallhäusser-Franke et al., 1995; Meade et al., 1998).

Although we found no qualitative differences between the cell types of the mammalian striatum and their counterparts in area $\mathrm{X}$, there are some quantitative differences that merit discussion. One such difference is the smaller soma size of all area $\mathrm{X}$ cell types relative to their analogs in the mammalian striatum. It is not clear what (if any) functional significance this distinction may have, but it is worth noting that the relative sizes among cell types are roughly the same; for example, SNs have the smallest somata and LA cells have the largest. Another apparent difference is a substantially higher input resistance of area X SNs relative to mammalian MSNs; we report SN resistances that are three to five times higher than those for MSNs studied using the whole-cell technique. Naturally, the smaller size of area X SNs could explain some of this difference, but there are also methodological differences that might artificially inflate the apparent disparity. Specifically, our input resistance is roughly the maximum subthreshold membrane resistance, whereas measurements in mammals were often made at potentials in which the inward rectification is

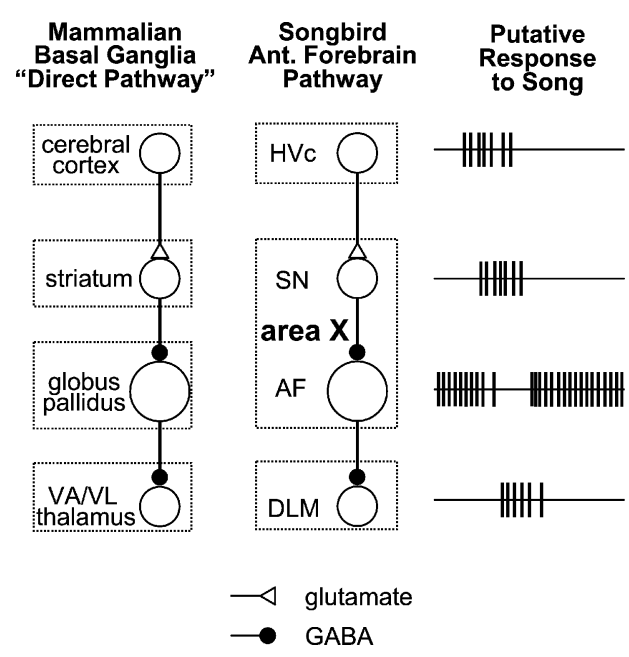

Figure 15. Our working hypothesis. Area X appears to be a mixture of striatum and globus pallidus. An excitatory response in the HVc may be transmitted to the DLM by two successive inhibitory synapses. Excitation of SNs by glutamatergic HVc input could inhibit the AF cells, briefly reducing their spontaneous activity. This would transiently reduce tonic inhibition in DLM neurons, allowing them to fire. In this manner, the AFP could act as a functional analog of the mammalian direct pathway through the basal ganglia. The projection from LMAN to area $\mathrm{X}$ is omitted for the sake of simplicity. $V A$, Ventral anterior; $V L$, ventral lateral.

active, thereby reducing membrane resistance. The mean resistance of our SNs in the "fully rectified" (hyperpolarized) state is $141 \mathrm{M} \Omega$, which is actually lower than at least some values reported for mammalian MSNs recorded using the whole-cell method (e.g., Kawaguchi, 1993). One last discrepancy that deserves comment is the relatively low proportion of SNs in our recordings (approximately two-thirds of the total); in mammals, SNs constitute at least $80 \%$ of the total neural population in the striatum and can constitute 90-95\% of striatal neurons (Gerfen, 1992; Parent and Hazrati, 1995). However, our recordings do not sample the cell types proportionately; our visually guided recordings targeted the larger interneurons, and SNs seemed more sensitive to the slicing process than the other cell types.

The overall quantitative differences between mammalian striatal neurons and the corresponding cell types in area $\mathrm{X}$ are minor and might be explained primarily by differences in experimental conditions such as temperature $\left(24-27^{\circ} \mathrm{C}\right.$ in the present study vs $34-37^{\circ} \mathrm{C}$ in most mammalian studies) or recording configuration (intracellular vs whole-cell). Nevertheless, there are two major differences between these structures: Area X has a fifth physiological cell type not found in the mammalian striatum (present results) and projects directly to the thalamus (Okuhata and Saito, 1987; Bottjer et al., 1989). Ironically, these two differences in effect cancel each other out. Area X appears to be a mixture of striatum and globus pallidus and we hypothesize that the "pallidal" cell type projects to the thalamus. We suggest that area $\mathrm{X}$ and its thalamic target may constitute a circuit that is equivalent to the "direct pathway" through the mammalian basal ganglia, with the striatal SNs receiving a glutamatergic "corticostriatal" input and making GABAergic synaptic contacts with pallidumlike neurons projecting to the thalamic nucleus DLM (Fig. 15). In this way, area $\mathrm{X}$ may retain the same functional organization as the mammalian basal ganglia while diverging from it in anatomical organization.

This arrangement could help to resolve the paradox concerning 
the transmission of auditory information through area X. Excitatory auditory responses to playback of the bird's own song have been recorded both upstream (HVc) and downstream [DLM and lateral magnocellular nucleus of the anterior neostriatum (LMAN)] of area X (McCasland and Konishi, 1981; Margoliash, 1983, 1986; Doupe and Konishi, 1991; Doupe, 1997), contradicting the perhaps simplistic expectation that the inhibitory projection of area $\mathrm{X}$ would convert an excitatory response into an inhibitory one. Our working hypothesis includes two successive inhibitory synapses on the pathway through area $\mathrm{X}$, so that an excitatory input would evoke APs in the striatal SNs, inhibiting tonic activity in the DLM-projecting AF cells, thereby transiently reducing inhibition in DLM neurons and allowing them to fire (Fig. 15). This process is enhanced by the intrinsic properties of DLM neurons; these neurons exhibit postinhibitory rebound and can fire simply on termination of a train of IPSPs (Luo and Perkel, 1999a). Postinhibitory rebound in the AF cells would help terminate this response quickly after inhibition from SNs ceases.

Our working hypothesis is consistent with what is known about area $\mathrm{X}$, but it is only a conjecture at this point. We make three key assumptions about the anatomical organization within area $\mathrm{X}$ that are as yet unproven: that HVc afferents innervate the SNs but not the AF cells, that the SNs directly inhibit the AF cells, and that the AF cells are in fact the projection neurons of area X. The second assumption seems quite reasonable given the large numbers of SNs in area X and the rarity of interneurons through which indirect communication between SNs and AF cells would have to occur. However, the first assumption is more questionable; in fact, we have some preliminary evidence of pallial (cortex-like) glutamatergic innervation of both SN and AF neurons (Farries and Perkel, 2000b). This may explain why tonically active, fast-firing neurons recorded from area $\mathrm{X}$ in vivo generally show an overall increase in firing rate during singing and playback of the bird's own song, interspersed with pauses in activity (Doupe, 1997; Hessler and Doupe, 1999; Solis and Doupe, 1999). Our working hypothesis probably represents only one of several possible routes through area $\mathrm{X}$, and more studies of anatomy and synaptic physiology will be necessary to answer the many questions about the organization of circuits within it.

Once one considers circuits through area $\mathrm{X}$ that differ from the simple one shown in Figure 15, one must also reconsider how closely area $\mathrm{X}$ matches the circuits known in the mammalian basal ganglia. First, a direct cortical projection to the globus pallidus is not a part of the classic direct pathway, although cortical projections to the mammalian pallidum do exist (Sesack et al., 1989; Naito and Kita, 1994). Furthermore, the known anatomy of area $\mathrm{X}$ does not seem to accommodate an "indirect pathway" that includes the external segment of the globus pallidus and the subthalamic nucleus, even if such a pathway exists in other parts of the avian basal ganglia (Jiao et al., 2000). Finally, it is not clear that area $\mathrm{X}$ and much of the rest of the avian basal ganglia are homologous to the parts of the mammalian basal ganglia that are most intimately connected with the isocortex, that is, the caudate, putamen, "dorsal" pallidum (internal and external segments of the globus pallidus, substantia nigra pars reticulata), and ventral tier nuclei of the thalamus. Much of the avian pallium, including the song system nuclei, may be homologous to the mammalian piriform cortex, claustrum, and pallial amygdala, but not to the isocortex (Striedter, 1997; Puelles et al., 2000). By the same token, avian subpallial structures, including area $\mathrm{X}$, might be more like mammalian ventral basal ganglia structures such as the nucleus accumbens, ventral pallidum, and extended amygdala (Farries and Perkel, 2000a).

Whatever organizational differences there may be, the fact remains that area $X$ contains all of the basic components of the mammalian sensorimotor basal ganglia with virtually identical physiological and histochemical properties. If area $\mathrm{X}$ is phylogenetically more closely related to ventral "limbic" basal ganglia than to dorsal sensorimotor regions, this may only imply that similar physiological mechanisms are used throughout the basal ganglia, and that its different regions differ primarily in their inputs and outputs, not in how those inputs are processed. In any case, the role of area $\mathrm{X}$ in birdsong appears to be sensorimotor, its phylogenetic affinities notwithstanding. Area X performs functions in birdsong that the mammalian basal ganglia are thought to perform in other behaviors, using very similar cell types. Moreover, the principal physiological cell types of area X (SN and AF) are also found in the avian basal ganglia outside of the song system (Farries and Perkel, 2000a). Our work suggests that the study of song learning will be more directly applicable to other forms of motor learning, in other vertebrate taxa, than even optimistic researchers had believed previously.

\section{REFERENCES}

Belleau ML, Warren RA (2000) Postnatal development of electrophysiological properties of nucleus accumbens neurons. J Neurophysiol 84:2204-2216.

Bengtson CP, Osborne PB (2000) Electrophysiological properties of cholinergic and noncholinergic neurons in the ventral pallidal region of the nucleus basalis in rat brain slices. J Neurophysiol 83:2649-2660.

Bennett BD, Wilson CJ (1999) Spontaneous activity of neostriatal cholinergic interneurons in vitro. J Neurosci 19:5586-5596.

Blanton MG, Lo Turco JJ, Kriegstein AR (1989) Whole cell recording from neurons in slices of reptilian and mammalian cerebral cortex. J Neurosci Methods 30:203-210.

Boettiger CA, Doupe AJ (1998) Intrinsic and thalamic excitatory inputs onto songbird LMAN neurons differ in their pharmacological and temporal properties. J Neurophysiol 79:2615-2628.

Bottjer SW, Miesner EA, Arnold AP (1984) Forebrain lesions disrupt development but not maintenance of song in passerine birds. Science 224:901-903.

Bottjer SW, Halsema KA, Brown SA, Miesner EA (1989) Axonal connections of a forebrain nucleus involved with vocal learning in zebra finches. J Comp Neurol 279:312-326.

Bottjer SW, Brady JD, Walsh JP (1998) Intrinsic and synaptic properties of neurons in the vocal-control nucleus LMAN from in vitro slice preparations of juvenile and adult zebra finches. J Neurobiol 37:642-658

Brainard MS, Doupe AJ (2001) Postlearning consolidation of birdsong: stabilizing effects of age and anterior forebrain lesions. J Neurosci 21:2501-2517.

Cepeda C, Walsh JP, Buchwald NA, Levine MS (1991) Neurophysiological maturation of cat caudate neurons: evidence from in vitro studies. Synapse 7:278-290.

Doupe AJ (1997) Song- and order-selective neurons in the songbird anterior forebrain and their emergence during vocal development. J Neurosci 17:1147-1167.

Doupe AJ, Konishi M (1991) Song-selective auditory circuits in the vocal control system of the zebra finch. Proc Natl Acad Sci USA 88:11339-11343.

Doya K (2000) Complementary roles of basal ganglia and cerebellum in learning and motor control. Curr Opin Neurobiol 10:732-739.

Edwards FA, Konnerth A, Sakmann B, Takahashi T (1989) A thin slice preparation for patch clamp recordings from neurones of the mammalian central nervous system. Pflügers Arch 414:600-612.

Farries MA, Perkel DJ (1998) Electrophysiological similarities between area $\mathrm{X}$ neurons in the zebra finch and neurons of the mammalian striatum. Soc Neurosci Abstr 24:191.

Farries MA, Perkel DJ (2000a) Electrophysiological properties of avian basal ganglia neurons recorded in vitro. J Neurophysiol 84:2502-2513.

Farries MA, Perkel DJ (2000b) Physiological properties of synapses in area X of the zebra finch. Soc Neurosci Abstr 26:2029.

Fortune ES, Margoliash D (1995) Parallel pathways and convergence onto HVc and adjacent neostriatum of adult zebra finches (Taeniopygia guttata). J Comp Neurol 360:413-441.

Gerfen CR (1992) The neostriatal mosaic: multiple levels of compart- 
mental organization in the basal ganglia. Annu Rev Neurosci 15:285320 .

Graybiel AM, Aosaki T, Flaherty AW, Kimura M (1994) The basal ganglia and adaptive motor control. Science 265:1826-1831.

Hessler NA, Doupe AJ (1999) Singing-related neural activity in a dorsal forebrain-basal ganglia circuit of adult zebra finches. J Neurosci 19:10461-10481.

Jiang Z-G, North RA (1991) Membrane properties and synaptic responses of rat striatal neurones in vitro. J Physiol (Lond) 443:533-553.

Jiao Y, Medina L, Veenman CL, Toledo C, Puelles L, Reiner A (2000) Identification of the anterior nucleus of the ansa lenticularis in birds as the homolog of the mammalian subthalamic nucleus. J Neurosci 20:6998-7010.

Kardong KV (1998) Vertebrates: comparative anatomy, function, evolution, Ed 2. Boston: McGraw-Hill.

Kawaguchi Y (1992) Large aspiny cells in the matrix of the rat neostriatum in vitro: physiological identification, relation to the compartments and excitatory postsynaptic currents. J Neurophysiol 67:1669-1682.

Kawaguchi Y (1993) Physiological, morphological, and histochemical characterization of three classes of interneurons in rat neostriatum. J Neurosci 13:4908-4923.

Kita T, Kita H, Kitai ST (1984) Passive electrical membrane properties of rat neostriatal neurons in an in vitro slice preparation. Brain Res 300:129-139.

Koós T, Tepper JM (1999) Inhibitory control of neostriatal projection neurons by GABAergic interneurons. Nat Neurosci 2:467-472.

Kubota Y, Kawaguchi Y (2000) Dependence of GABAergic synaptic areas on the interneuron type and target size. J Neurosci 20:375-386.

Livingston FS, Mooney R (1997) Development of intrinsic and synaptic properties in a forebrain nucleus essential to avian song learning. J Neurosci 17:8997-9009.

Luo M, Perkel DJ (1999a) A GABAergic, strongly inhibitory projection to a thalamic nucleus in the zebra finch song system. J Neurosci 19:6700-6711.

Luo M, Perkel DJ (1999b) Long-range GABAergic projection in a circuit essential for vocal learning. J Comp Neurol 403:68-84.

Margoliash D (1983) Acoustic parameters underlying the responses of song-specific neurons in the white-crowned sparrow. J Neurosci 3:1039-1057

Margoliash D (1986) Preference for autogenous song by auditory neurons in a song system nucleus of the white-crowned sparrow. J Neurosci 6:1643-1661.

McCasland JS, Konishi M (1981) Interaction between auditory and motor activities in an avian song control nucleus. Proc Natl Acad Sci USA 78:7815-7819.

Meade CA, Bottjer SW, Cuthbertson SL, Reiner A (1998) Organization of neurotransmitter-specific neurons in area $\mathrm{X}$ of the male zebra finch basal ganglia. Soc Neurosci Abstr 24:1698.

Medina L, Reiner A (1995) Neurotransmitter organization and connectivity of the basal ganglia in vertebrates: implications for the evolution of basal ganglia. Brain Behav Evol 46:235-258.

Naito A, Kita H (1994) The cortico-pallidal projection in the rat: an anterograde tracing study with biotinylated dextran amine. Brain Res 653:251-257.

Nakanishi H, Kita H, Kitai ST (1990) Intracellular study of rat entopeduncular nucleus neurons in an in vitro slice preparation: electrical membrane properties. Brain Res 527:81-88.

Nisenbaum ES, Wilson CJ (1995) Potassium currents responsible for inward and outward rectification in rat neostriatal spiny projection neurons. J Neurosci 15:4449-4463.

Nisenbaum ES, Xu ZC, Wilson CJ (1994) Contribution of a slowly inactivating potassium current to the transition to firing of neostriatal spiny projection neurons. J Neurophysiol 71:1174-1189.

Nixdorf-Bergweiler BE, Lips MB, Heinemann U (1995) Electrophysiological and morphological evidence for a new projection of LMANneurones towards area X. NeuroReport 6:1729-1732.

Nottebohm F, Stokes TM, Leonard CM (1976) Central control of song in the canary, Serinus canarius. J Comp Neurol 165:457-486.

Nottebohm F, Kelley DB, Paton JA (1982) Connections of vocal control nuclei in the canary telencephalon. J Comp Neurol 207:344-357.

Okuhata S, Saito N (1987) Synaptic connections of thalamo-cerebral vocal nuclei of the canary. Brain Res Bull 18:35-44.

Parent A, Hazrati L-N (1995) Functional anatomy of the basal ganglia. I. The cortico-basal ganglia thalamo-cortical loop. Brain Res Brain Res Rev 20:91-127.

Puelles L, Kuwana E, Puelles E, Bulfone A, Shimamura K, Keleher J, Smiga S, Rubenstein JLR (2000) Pallial and subpallial derivatives in the embryonic chick and mouse telencephalon, traced by the expression of the genes Dlx-2, Emx-1, Nkx-2.1, Pax-6, and Tbr-1. J Comp Neurol 424:409-438.

Scharff C, Nottebohm F (1991) A comparative study of the behavior deficits following lesions of various parts of the zebra finch song system: implications for vocal learning. J Neurosci 11:2896-2913.

Sesack SR, Deutch AY, Roth RH, Bunney BS (1989) Topographical organization of the efferent projections of the medial prefrontal cortex in the rat: an anterograde tract-tracing study with Phaseolus vulgaris leucoagglutinin. J Comp Neurol 290:213-242.

Sohrabji F, Nordeen EJ, Nordeen KW (1990) Selective impairment of song learning following lesions of a forebrain nucleus in juvenile zebra finches. Behav Neural Biol 53:51-63.

Solis MM, Doupe AJ (1999) Contributions of tutor and bird's own song experience to neural selectivity in the songbird anterior forebrain. J Neurosci 19:4559-4584.

Stark LL, Perkel DJ (1999) Two-stage, input-specific synaptic maturation in a nucleus essential for vocal production in the zebra finch. J Neurosci 19:9107-9116.

Striedter GF (1997) The telencephalon of tetrapods in evolution. Brain Behav Evol 49:179-213.

Uchimura N, Cherubini E, North RA (1989) Inward rectification in rat nucleus accumbens neurons. J Neurophysiol 62:1280-1286.

Vates GE, Nottebohm F (1995) Feedback circuitry within a songlearning pathway. Proc Natl Acad Sci USA 92:5139-5143.

Wallhäusser-Franke E, Collins CE, DeVoogd TJ (1995) Developmental changes in the distribution of NADPH-diaphorase-containing neurons in telencephalic nuclei of the zebra finch song system. J Comp Neurol 356:345-354.

White SA, Livingston FS, Mooney R (1999) Androgens modulate NMDA receptor-mediated EPSCs in the zebra finch song system. J Neurophysiol 82:2221-2234.

Wild JM (1993) Descending projections of the songbird nucleus robustus archistriatalis. J Comp Neurol 338:225-241.

Zahm DS, Zaborszky L, Alheid GF, Heimer L (1987) The ventral striatopallidothalamic projection. II. The ventral pallidothalamic link. J Comp Neurol 255:592-605.

Zuschratter W, Scheich H (1990) Distribution of choline acetyltransferase and acetylcholinesterase in the vocal motor system of zebra finches. Brain Res 513:193-201. 